Neurolmages

A
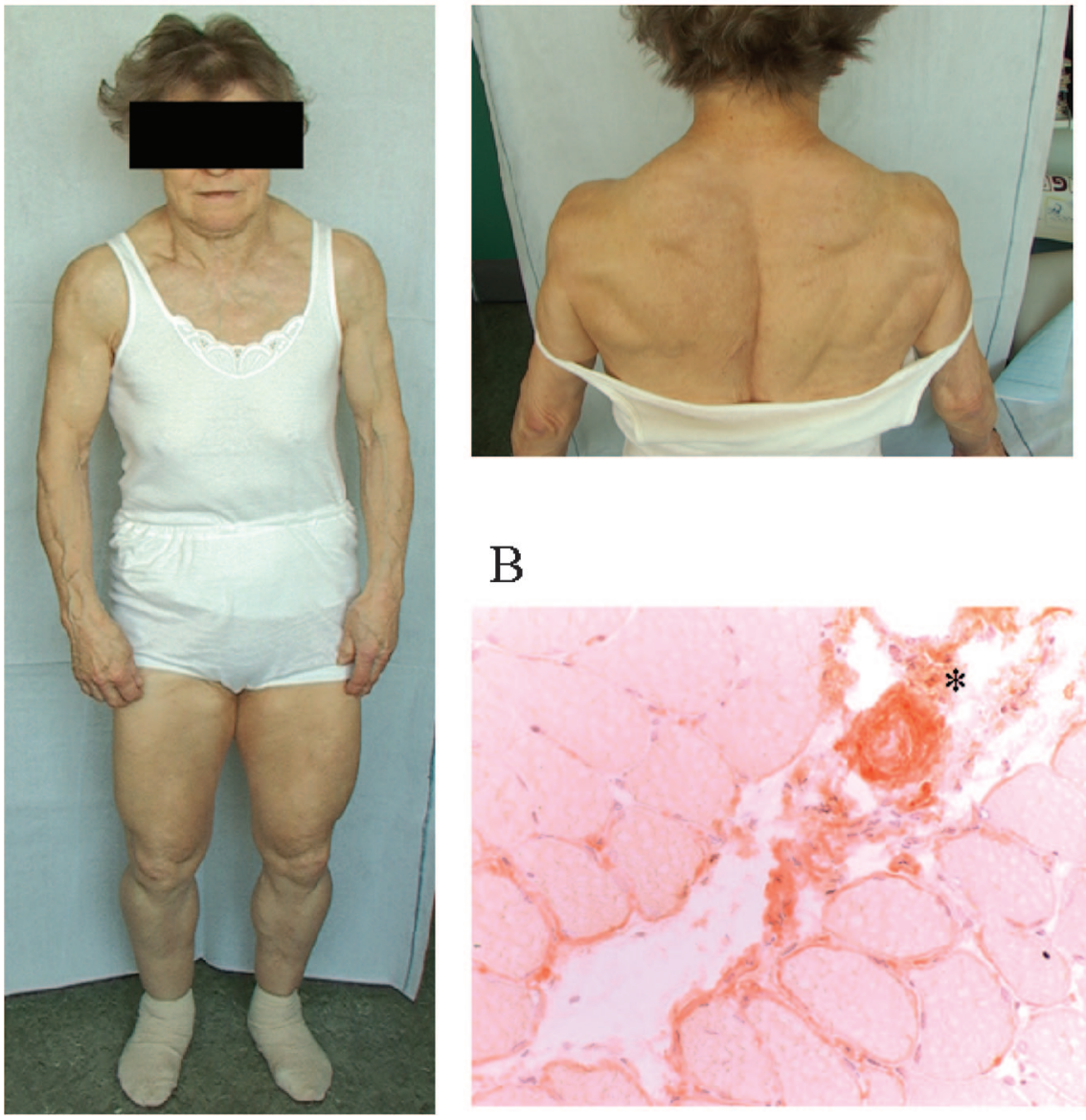

B

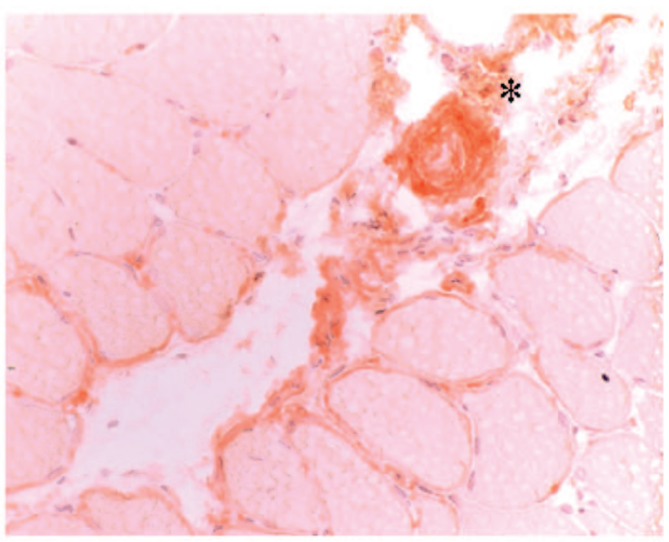

Figure. (A) A body-builder-like appearance of muscles and reduction of subcutaneous fat in a 73-year-old nonexercising woman. (B) Congo red staining of muscle (vastus lateralis) revealed congophilia (red staining) of blood vessel walls (asterisk) and endomysium.

\section{Gross muscle pseudohypertrophy in myeloma-associated light chain amyloidosis}

Anja Windhagen, MD; Johannes Bufler, MD; and Stefan Neudecker, MD, Hannover and Halle/Saale, Germany

A 73-year-old woman developed muscle enlargement, stiffness, and signs of congestive heart failure over 2 years (figure, A). Examination revealed proximal weakness and reduction of subcu-

Disclosure: The authors report no conflicts of interest.

Received April 1, 2005. Accepted in final form June 24, 2005.

Address correspondence and reprint requests to Dr. A. Windhagen, Department of Neurology, Medical School Hannover, Carl-Neuberg-Str. 1, 30625

Hannover, Germany; e-mail: windhagen.anja@mh-hannover.de taneous fat. Macroglossia was absent. Endocrinology was normal.Muscle biopsy showed amyloid deposition (figure, B), and a plasmacytoma with $\lambda$ light chain paraprotein was revealed. Melphalan/prednisolone resulted in reduction of muscle bulk; however, death from cardiac failure occurred 12 months later (autopsy not performed).

Amyloid myopathy is a rare manifestation of systemic amyloidosis. ${ }^{1}$ Muscle enlargement ("pseudohypertrophy") was reported in 7 to $44 \%$ of cases. $^{2}$ Amyloid deposition in our patient was not extensive, suggesting that more specific effects of the paraprotein on regulation of muscle homeostasis might explain the unusual phenotype.

1. Chapin JE, Kornfeld M, Harris A. Amyloid myopathy: characteristic features of a still underdiagnosed disease. Muscle Nerve 2005;31:266 272.

2. Spuler S, Emslie-Smith A, Engel AG. Amyloid myopathy: an underdiagnosed entity. Ann Neurol 1998;43:719-728. 


\section{Neurology}

\section{Gross muscle pseudohypertrophy in myeloma-associated light chain amyloidosis}

Anja Windhagen, Johannes Bufler and Stefan Neudecker

Neurology 2005;65;1670

DOI 10.1212/01.wnl.0000182297.15699.2e

\section{This information is current as of November 21, 2005}

\section{Updated Information \&} Services

References

Permissions \& Licensing

Reprints including high resolution figures, can be found at: http://n.neurology.org/content/65/10/1670.full

This article cites 2 articles, 0 of which you can access for free at: http://n.neurology.org/content/65/10/1670.full\#ref-list-1

Information about reproducing this article in parts (figures,tables) or in its entirety can be found online at:

http://www.neurology.org/about/about_the_journal\#permissions

Information about ordering reprints can be found online: http://n.neurology.org/subscribers/advertise

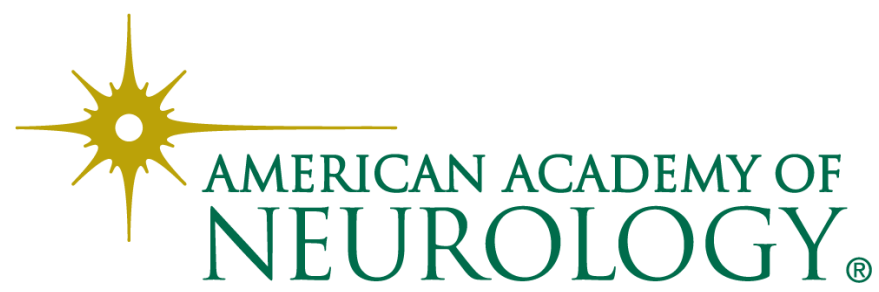

